DOI: $10.17805 / z p u .2016 .2 .18$

\title{
Методология исследования численности аппарата государственной службы России (1984-2014 гг.)
}

\author{
Г. А. БОРЩЕВСКИЙ \\ ( РОССИЙСКАЯ АКАДЕМИЯ НАРОДНОГО ХОЗЯЙСТВА \\ И ГОСУДАРСТВЕННОЙ СЛУЖБЫ ПРИ ПРЕЗИДЕНТЕ РФ)
}

В статье рассмотрена динамика численности работников российских органов государственного управления в 1984-2014 гг. Выдвинута гипотеза о том, что численность кадров является важным индикатором эффективности реформирования государственной службы. Данные о соотношении численности различных групп государственных служащих, доле государственных служащих в общей численности населения страны и среди занятых в экономике способны пролить свет на тенденции реформирования аппарата государственной службы, изменение ее места и роли в российском обществе.

Ввиду высокой инертности системы государственной службы изменения в ней происходят медленно, изучать их следует на больших промежутках времени начиная от нескольких десятилетий. Объектом изучения в данной работе являются кадры центральных (федеральных) министерств и ведомств, так как именно они составляли ядро системы государственной службы и в годы социализма, и в новейший период.

Разработана и апробирована методика определения численности государственных служащих по сопоставимым группам с точки зрения исполняемых функций, которая позволяет преодолевать различия в правовом содержании понятия государственной службы в хронологических рамках исследования. На основании материалов статистических наблюдений собраны и классифицированы данные о численности различных групп государ- 
ственных служащих. Прослежена их динамика, выявлены общие тенденции. Отмечено возрастание бюрократизации российского общества в 1990-е и особенно в 2000-е годы. Вместе с тем доказано, что численность государственных и муниципальных служащих в 1984 г. практически равнялась аналогичному показателю 2014 г.

Обнаружено существование положительной связи между общей численностью населения, числом занятых в экономике и численностью государственных служащих, а также между численностью государственных служащих и динамикой среднедушевого ВВП. Это свидетельствует о том, что изменение численности государственных служащих исторически происходит в общем русле социально-экономического развития страны.

Выявленные тенденции могут быть использованы при проведении дальнейших исследований. В частности, перспективным представляется проведение сопоставительного анализа динамики численности государственных служащих и динамики оплаты их труда, а также исследование численности аппарата на фоне изменения количества государственных функций. Подобный анализ позволит выработать методологические основания для проектирования конкретных мероприятий по повышению эффективности реформирования государственной службы с учетом выявленных эмпирических закономерностей ее развития.

Ключевые слова: Россия; методология; государственная служба; чиновничество; бюрократия; аппарат управления; социально-экономическое развитие

\section{ВВЕАЕНИЕ}

Dеформирование системы государственной службы - перманентный процесс. Иногда политические изменения способствуют его активизации, в остальное время он происходит медленнее, однако госслужба непрерывно изменяется вместе с обществом.

Чтобы понять характер происходящих изменений в России и прогнозировать их в будущем, следует выявить существующие закономерности в ходе развития государственной службы. Одним из индикаторов эффективности реформирования является численность персонала государственной службы в абсолютном и относительном выражении. Базой для сравнения при этом являются значения показателей в прошлые годы, т. е. исторические сопоставления. Они позволяют понять, как меняется место госслужбы в обществе по мере проведения реформ.

Изменения в системе государственной службы происходят медленно, поэтому поиск закономерностей в ее развитии следует осуществлять на больших промежутках времени - несколько десятилетий и более. Однако здесь встречаются методологические затруднения, так как только в ХХ в. действовали три системы государственной службы - имперская, советская и новая российская, каждая из которых имела свои особенности.

Опыт дореволюционной госслужбы хорошо изучен (Мельников, Нечипоренко, 2006), есть исследования и о численности чиновничества (Зайончковский, 1978). Однако непосредственно соотнести их с современными данными невозможно, минуя советский период.

Складывание в СССР партийно-номенклатурного принципа государственной кадровой политики начиная со второй половины 1920-х годов привело к возникновению особой модели государственной службы. Ранний период ее существования сравнительно хорошо изучен в теоретическом плане (напр.: Оболонский, 2015), но пока не стал предметом серьезного количественного анализа. Фактические данные по численности советской бюрократии носят экспертный характер и существенно разнятся в зависимости от того, на каких методологических позициях стоит автор каждой конкретной работы. 
Если говорить о последних десятилетиях существования СССР, то тут также нет единства мнений относительно численности государственного аппарата. Например, Ю.А. Розенбаум указывал, что в аппарате государственного управления работало более 10 млн трудящихся (Розенбаум, 1975: 21), подразумевая под трудящимися ответственных работников хозяйственной сферы. М.С. Восленский приводит цифру 5-6 млн человек, характеризующую численность работников номенклатуры в 1950-1980-е годы (Восленский, 1991: 150-151).

Ряд современных исследователей оценивают численность аппарата органов управления СССР середины - второй половины 1980-х годов в 2,4 млн человек (Калабеков, 2010; Соколов, Терентьев, 2014: Электронный ресурс; «С госслужбы не ухоАят», 2015).

Подобную разноголосицу мнений породило отсутствие четкого определения понятия госслужбы в советском законодательстве и вызванное этим отсутствие официальной статистики по численности государственных служащих. В то же время никто не отрицает, что в советское время государственная служба существовала как явление, пусть и не оформленное юридически.

Отсутствие специального законодательства в 1991-1993 гг. также мешало авторам проанализировать численность аппарата государственной службы в этот важнейший период. Начиная с 1994 г. исследования о численности госслужащих есть, но они несопоставимы с современными данными ввиду изменения методик статистического наблюдения.

Таким образом, имеющиеся отрывочные сведения о численности государственных служащих предыдущих периодов невозможно непосредственно сопоставить с численностью аппарата управления РФ сегодня. Между тем подобное сопоставление необходимо для того, чтобы составить целостное представление о ходе развития отечественного государственного аппарата, происходившего в общем контексте социально-экономических и политических изменений в российском обществе.

\section{МЕТОАОАОГИЯ ИССАЕАОВАНИЯ}

В качестве основания для подобного сопоставления мы предлагаем рассматривать функции, выполняемые госслужащими в их современном понимании, а именно деятельность по обеспечению исполнения полномочий государственных органов и лиц, замещающих государственные должности (Федеральный закон ..., 2003: Электронный ресурс). Аалее, следует выделить группы работников, выполнявших сопоставимые по содержанию функции в рамках системы управления, существовавшей в преАшествующий исторический период. Таким образом, на наш взгляд, удастся преодолеть различия в правовых рамках госслужбы и выделить то общее, что было всегда присуще ей как системе.

Исходя из данной методики, нами была разработана матрица соответствий между группами должностей в современной системе управления и в аналогичных системах, действовавших в 1980-1990 гг. Аля всего хронологического периода используется современная терминология. Матрица состоит из трех групп:

1) лица, замещающие государственные и муниципальные должности;

2) гражданские служащие РФ и субъектов РФ в органах исполнительной власти,;

3) гражданские служащие в федеральных органах исполнительной власти.

Каждая следующая группа входит в состав предыдущей. Принципиальная возможность соотнесения должностей советской и современной государственной службы 
в рамках приведенной группировки зафиксирована в указе Президента РФ (Указ ... , 2010: Электронный ресурс).

Объем статьи не позволяет привести матрицу полностью. Рассмотрим здесь лишь ее часть, касающуюся должностей гражданской службы в федеральных органах исполнительной власти (ФОИВ). Их аналогами считаются:

- до 1991 2. - должности штатного административного персонала (без персонала по охране и обслуживанию зданий) гражданских министерств и ведомств в ведении Совета Министров РСФСР, а также аналогичный персонал союзного подчинения, исполнявший полномочия на территории РСФСР 1 . В качестве аналога центрального аппарата (ЦА) ФОИВ учитывался аппарат указанных министерств и ведомств, расположенный в Москве; аналогом территориальных органов (ТО) ФОИВ был аппарат органов хозяйственного управления (инспекций и территориальных управлений центральных министерств и ведомств). Работники партийных и общественных органов, исполнявших в СССР управленческие функции, не включены в предлагаемую классификацию, так как не имеют прямого соответствия в современной системе государственного управления РФ;

- 8 1992-1993 22. - штатные административные должности в аппарате гражданских министерств и ведомств РФ (аналог ЦА) и аналогичные должности в окружном, районном, городском аппарате министерств и ведомств РФ (аналог ТО);

- 8 1994-2014 22. - должности федеральной государственной службы в органах исполнительной власти, кроме должностей военной и правоохранительной службы.

Аналогичным образом были выявлены соответствия для других групп классификации.

\section{ОСНОВНЫЕ РЕЗУАЬТАТЫ ИССАЕАОВАНИЯ}

Аалее была решена исследовательская задача по выявлению конкретной численности работников каждой группы. Использовались сборники официальной статистики, но для определения значения каждого показателя проводилась перегруппировка данных, исходя из разработанной классификации (например, исключались группы, не входящие в классификацию). Ряд данных был получен нами в Федеральной службе государственной статистики РФ. В результате нам удалось собрать относительно полные данные по годам (см. таблицу, с. 212).

Обращает внимание сопоставимость численности работников государственных и муниципальных органов вначале и в конце анализируемого периода.

Как видно, на середину 1990-х годов пришлось наибольшее снижение численности служащих, особенно в органах исполнительной власти. Эти данные расходятся с оценками ряда авторов, указывающих на рост бюрократии в 1990-е годы (Гимпельсон, 2002: 30). Расхождение вызвано тем, что эти исследователи учитывали численность работников аппарата вместе с обслуживающим персоналом, а мы - без него, что более корректно.

Причиной сокращения численности госслужащих до 1998 г. стало, на наш взгляд, ухудшение материального положения, вследствие чего до половины от всех вакансий в исполнительных органах в тот период оставались незаполненными.

Резкое снижение численности работников представительных органов между 1988 и 1991 гг. (см. таблицу) объясняется ликвидацией системы советских органов. В дальнейшем параметры этой группы оставались стабильными. В группе судебных органов наблюдался постепенный рост численности работников до 2013 г. 


\begin{tabular}{|c|c|c|c|c|}
\hline \multirow{9}{*}{ 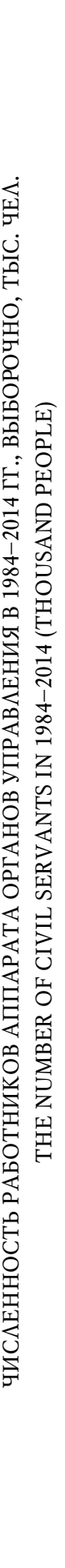 } & 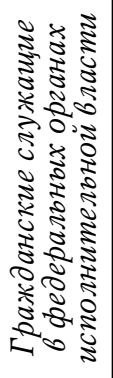 & & 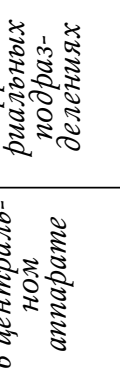 & 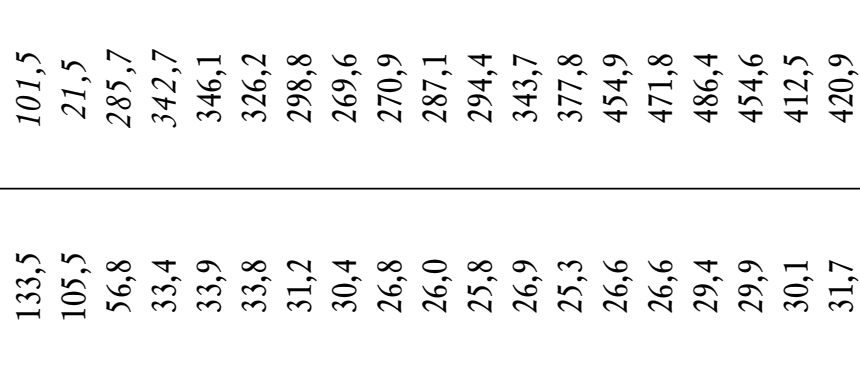 \\
\hline & \multirow{3}{*}{ 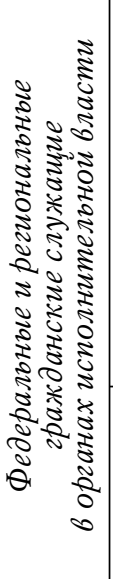 } & \multirow{2}{*}{ 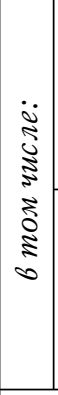 } & 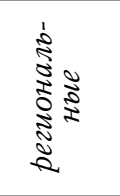 & 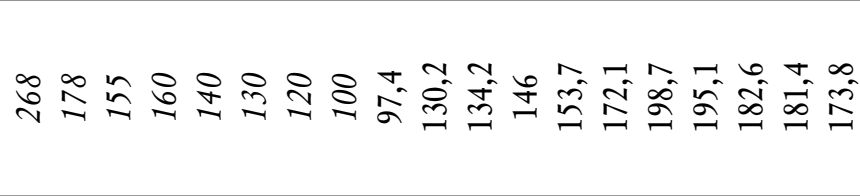 \\
\hline & & & 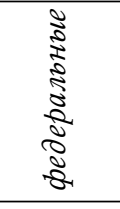 & 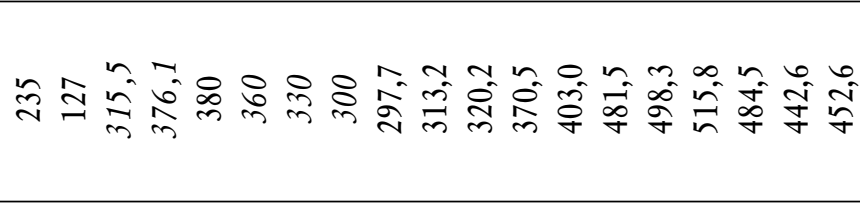 \\
\hline & & \multicolumn{2}{|r|}{ 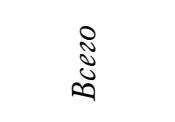 } & 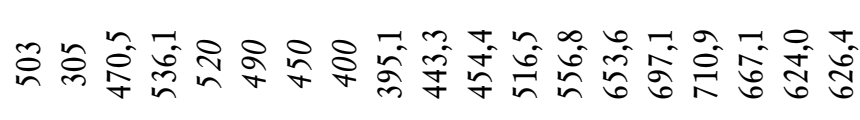 \\
\hline & \multirow{4}{*}{ 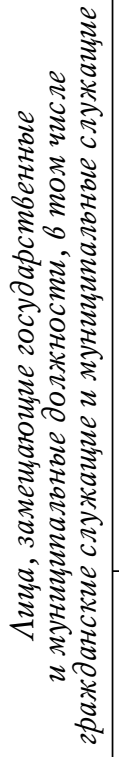 } & \multirow{3}{*}{ 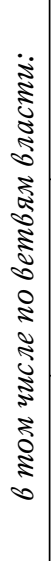 } & 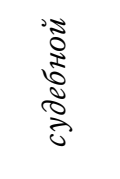 & 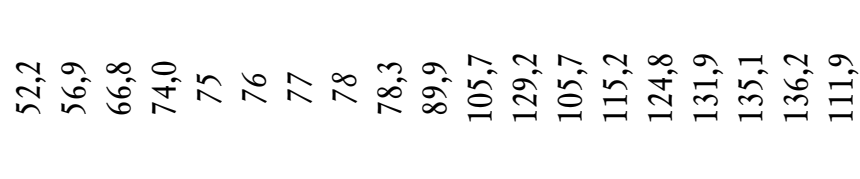 \\
\hline & & & 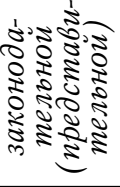 & 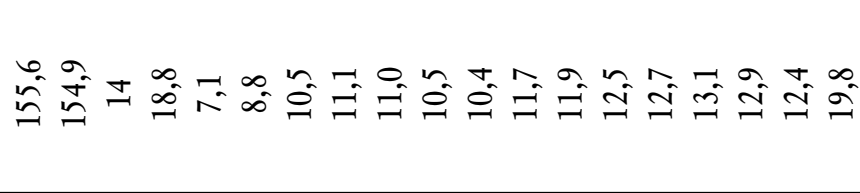 \\
\hline & & & 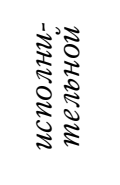 & 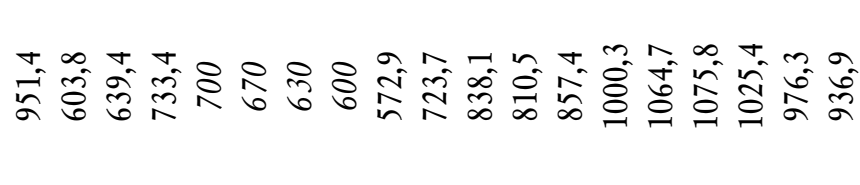 \\
\hline & & & 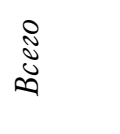 & 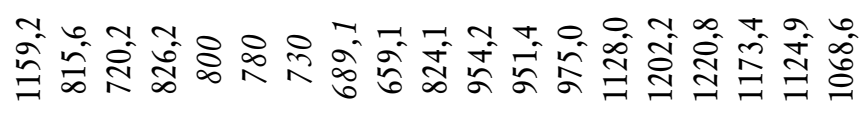 \\
\hline & & 8 & & 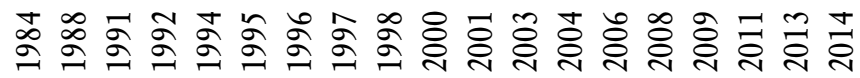 \\
\hline
\end{tabular}


Так как основная масса государственных служащих на протяжении всего периода концентрировалась в системе исполнительных органов, представляется важным более детально проанализировать их динамику.

Из представленных в таблице данных видны интересные тенденции.

Тренды изменения всех анализируемых показателей, кроме ЦА ФОИВ, совпадают. В 1984-1988 гг. наблюдалось снижение показателей, 1988-1992 гг. - их рост, в 1992-1998 гг. - новое снижение и в 1998-2009 гг. - рост. Аалее произошло очередное снижение, завершившееся ростом численности ТО ФОИВ в 2013-2014 гг., в то время как численность региональной госслужбы продолжала сокращаться. Численность госслужащих в ЦА ФОИВ резко сократилась в 1984-1992 гг. и с тех пор остается относительно стабильной.

В начальный период численность ЦА и численность ТО ФОИВ почти совпадала. Это же можно сказать о численности региональных и федеральных госслужащих. В дальнейшем количество госслужащих органов исполнительной власти (ОИВ) субъектов РФ несколько сократилась, а численность федеральных служащих существенно выросла за счет территориального аппарата. Принимая во внимание опережающий рост численности федеральных органов по отношению к органам субъектов РФ, виден ресурс для оптимизации численности федеральной государственной службы путем сокращения территориальных органов с передачей их функций органам субъектов РФ.

Значительное превышение численности лиц, замещающих государственные и муниципальные должности, над общей численностью гражданских служащих достигается за счет работников органов местного самоуправления. Численность лиц, замещавших государственные должности, не могла существенно сказаться на общих показателях, так как их всего порядка 30 тыс. человек; более $90 \%$ этих лиц - судьи.

Знание данных процессов важно для обеспечения более сбалансированного и планомерного развития системы государственной службы в будущем. Однако по одним лишь внутренним кадровым процессам нельзя судить об эффективности реформирования государственной службы. Следует определить, в каком социально-экономическом контексте протекают описанные реформы.

Аля решения этой задачи данные изменения численности государственной службы рассмотрены на фоне динамики трех макроэкономических показателей: численности населения, ВВП на душу населения и численности занятых в экономике. Выяснено, что сокращение численности населения сопровождалось сокращением численности занятых в 1992-2000 гг., в 2000-2009 гг. численность занятых начала расти, а с 2009 г. стала увеличиваться и численность населения.

Аинамика численности групп работников аппарата управления в основном совпадала: до 1998 г. эти показатели в целом снижались одновременно с сокращением численности населения и занятых в экономике. В 1998-2009 гг. динамика всех показателей снова совпадает, на этот раз в росте. После 2009 г. численность аппарата всех государственных и муниципальных органов и гражданских служащих ОИВ субъектов РФ сокращается на фоне роста численности населения и количества занятых. Численность гражданских служащих ФОИВ в 2009-2013 гг. тоже сокращалась, а в 2013-2014 гг. начала расти.

Можно констатировать, что изменение численности государственных служащих в анализируемом периоде происходит в общем русле динамики численности населения и рынка труда. Это отрадный и ожидаемый результат. 
То же можно сказать в связи с динамикой среднедушевого ВВП, который характеризует общую тенденцию социально-экономического развития страны. Общее снижение ВВП в 1991-2000 гг. в основном совпало с сокращением численности аппарата управления, а увеличение в 2000-2008 гг. - с ростом аппарата. В 2008-2014 гг. размер ВВП изменялся противоречиво, что совпало с неоднозначной динамикой численности работников аппарата. В будущем надо двигаться к усилению корреляции между численностью госслужащих и показателями развития экономики. Это важный индикатор для повышения доверия населения к власти.

Степень бюрократизации российского общества на различных этапах его развития показывают данные о доле государственных служащих в общей численности населения и в численности занятых.

Анализ статистических данных и архивных источников, выполненный нами с использованием описанной выше методологии, показывает, что группа служащих государственных и муниципальных органов была наиболее многочисленной по отношению к численности населения накануне перестройки, а также в конце 2000-х годов.

Наиболее резко удалось сократить аппарат управления в период 1985-1991 гг. на фоне роста численности населения. Минимальной была доля аппарата по отношению к численности населения в 1998 г. При этом следует отметить, что все колебания данного параметра укладываются в диапазон от 0,4 до $0,8 \%$ от общей численности населения. Если рассматривать численность федеральных гражданских служащих в ФОИВ, то она изменялась в тех же направлениях, что и численность всего аппарата государственного и муниципального управления, но в диапазоне от 0,1 до $0,2 \%$ от численности населения.

Пропорционально численности занятых в экономике общая динамика показателей была такой же. Минимальное значение доли работников аппарата государственных и муниципальных органов зафиксировано в 1991 г. (менее $1 \%$ ), максимальное в 2009 г. (1,75\%). Аоля численности гражданских служащих ФОИВ относительно численности занятых колебалась от 0,1 до $0,6 \%$. Таким образом, в 1990 -е и особенно в 2000-е годы произошел рост бюрократизации общества, однако картина эта не так страшна, как ее описывают в публицистической литературе.

\section{ЗАКАЮЧЕНИЕ}

По итогам проведенного анализа можно сформулировать следующие основные выводы.

1. Разработанная методика для определения сопоставимой численности государственных служащих позволяет определить, как изменялась численность госслужащих и имелись ли в этом процессе закономерности.

2. Выяснено, что численность государственных и муниципальных служащих в стране в 1984 г. практически равнялась аналогичному показателю 2014 г., а на середину 1990-х годов пришлось снижение численности госслужащих. В официальной статистике учитывалась численность обслуживающего персонала государственных органов, вследствие чего наблюдался рост количественных показателей. Отсюда делаются неверные выводы о росте численности бюрократии, однако на деле аппарат в тот период сократился ввиду неблагоприятных материальных условий и нестабильной кадровой ситуации. В свою очередь, в 2014 г. численность гражданских служащих в ОИВ по РФ превосходила численность аналогичного аппарата в 1984 г. по РСФСР на $20 \%$ и в 1988 г. - в два раза. Аанный нетривиальный вывод получен впервые на основании 
сопоставления численности служащих, исполнявших сопоставимые функции в соответствующие периоды времени.

3. Выявлено, что аппарат ФОИВ увеличивался более быстрым темпами и всегда превосходил по численности аппарат ОИВ субъектов РФ. Изменения численности федеральных органов были обусловлены практически исключительно изменениями в их ТО.

4. Обнаружено существование положительной связи между общей численностью населения, числом занятых в экономике и численностью государственных служащих, а также между численностью госслужащих и динамикой среднедушевого ВВП. Это свидетельствует о том, что динамика численности аппарата государственной службы в целом соответствовала тенденциям социально-экономического развития страны.

5. В результате расчета доли численности государственных служащих в численности населения и занятых в экономике отмечено возрастание бюрократизации российского общества в 1990-е и особенно в 2000-е годы. Сокращение численности госслужащих в 2010-2013 гг. не компенсировало этот процесс вследствие медленного прироста численности населения и занятых в экономике. При этом все рассмотренные соотношения увеличились между 1984 и 2014 гг. лишь от 0,1 до 1,75\% в зависимости от сравниваемых групп работников. Наиболее существенно увеличивалась численность аппарата ФОИВ.

Полученные данные дополняют картину реформирования государственной службы в России. Понимая имеющиеся погрешности в проведенном анализе, надеемся, что выявленные тенденции будут использованы при проведении дальнейших, более углубленных исследований. В частности, перспективным представляется проведение сопоставительного анализа динамики численности государственных служащих и динамики оплаты их труда, а также исследование численности аппарата на фоне изменения количества государственных функций. Подобный анализ позволит выработать методологические основания для проектирования конкретных мероприятий по повышению эффективности реформирования госслужбы с учетом выявленных эмпирических закономерностей ее развития.

\section{ПРИМЕЧАНИЕ}

1 Органы союзного значения учитываются, так как республиканские органы РСФСР не выполняли многих функций, которые после распада СССР перешли к Российской Федерации (обеспечение безопасности, таможенное регулирование, стандартизация, эмиссия денег и др.). Чтобы получить представление о численность аппарата, решавшего сопоставимый круг задач, следует учитывать аппарат как союзного, так и республиканского уровня, действовавший на территории РСФСР.

\section{СПИСОК АИТЕРАТУРЫ}

Федеральный закон от 27 мая 2003 г. № 58-Ф3 «О системе государственной службы Российской Федерации» // Собрание законодательства РФ. 2003. 2 июня. № 22. Ст. 2063 [Электронный pecypc]. URL: http://www.szrf.ru/doc.phtml?nb=edition00\&issid=2004031000\&docid=41 (дата обращения: 30.03.2015).

Указ Президента РФ от 20 сентября 2010 г. № 1141 «О перечне должностей, периоды службы (работы) в которых вкдючаются в стаж государственной гражданской службы для назначения пенсии за выслугу лет федеральных государственных гражданских служащих» // Собрание законодательства РФ. 2010. 27 сентября. № 39. Ст. 4926 [Электронный ресурс]. URL: http://www.szrf. $\mathrm{ru} /$ doc.phtml?nb=edition00\&issid=2010039000\&docid=57 (дата обращения: 30.03.2015).

«С госслужбы не уходят» (2015) / Александр Аьвович Сафонов ; беседовала Светлана Сухова // Огонек. № 16. С. 16-17. 
Восленский, М. С. (1991) Номенклатура. Господствующий класс Советского Союза. М. : Советская Россия. 624 с.

Гимпельсон, В. Е. (2002) Численность и состав российской бюрократии: Между советской номенклатурой и госслужбой гражданского общества. М. : ГУ-ВШЭ. 40 с.

Зайончковский, П. А. (1978) Правительственный аппарат самодержавной России в XIX в. М. : Мысль. 288 с.

Калабеков, И. Г. (2010) Российские реформы в цифрах и фактах. 2-е изд. М. : РУСАКИ. 270 с.

Мельников, В. П., Нечипоренко, В. С. (2006) Государственная служба в России: отечественный опыт организации и современность. М. : РАГС. 506 с.

Оболонский, А. В. (2015) Очерк истории российско-советской бюрократической номенклатуры // Вопросы государственного и муниципального управления. № 3. С. 145-164.

Розенбаум, Ю. А. (1975) К понятию управленческих кадров // Правоведение. № 6. С. 20-25.

Соколов, А., Терентьев, И. (2014) Исследование РБК: Сколько в России чиновников и много ли они зарабатывают? [Электронный ресурс]// PБK. 15 октября. URL: http://top.rbc.ru/economics/15/10/2014/543cfe56cbb20f8c4e0b98f2 (дата обращения: 29.04.2015).

Аата поступления: 20.10.2015 2.

\section{RESEARCH METHODOLOGY FOR ASSESSING THE NUMBER}

OF CIVIL SERVANTS IN RUSSIA (1984-2014)

\section{G. A. BORSHCHEVSKII}

\section{(Russian Presidential Academy of National Economy and Public Administration, Moscow)}

The article deals with the dynamics of the changes in the number of employees at Russia's governmental bodies in the years 1984 to 2014. Our research hypothesis was that the number of employees is an important indicator of the efficiency of the civil service reform. The ratio between the sizes of various civil servant groups, as well as the share of civil servants in the total population and the labor force, can shed light on the trends in civil service reforms and on its changing place in Russian society.

Due to the high inertia of the civil service, systemic transformations there happen slowly. Thus they should be studied over large intervals of time (several decades or longer). The object of our study are the employees of federal ministries and departments which have constituted the core of the civil service both in Soviet and post-Soviet years.

We have designed and tested a methodology to assess the number of civil servants in comparable groups in terms of functions performed. This allowed us to overcome the differences in legal understandings of public service throughout the chronological framework of the study. The statistical materials obtained and the data on different groups of civil servants helped us assess their number, classify them into categories, as well as identify general trends in the dynamics of transformation.

The 1990s and especially the 2000s saw a marked increase in the bureaucratization of the Russian society. At the same time, we have shown that the number of state and municipal employees in 1984 and 2014 was almost equal.

We have traced a positive correlation between the total population, the labor force with an employment and the number of civil servants, as well as between the number of the latter and the dynamics of per capita GDP. This indicates that army of civil servants grows larger or smaller historically in accordance with the mainstream trends in the socio-economic development of the country.

The trends identified in this article provide a ground for further research. It seems especially promising to conduct a comparative analysis of the change in the number of civil servants and in their earnings, as well as a study of how the dynamics of civil servants' number correlates with an expansion or contraction of the functions of the state. Taking into account the empirical factors of the development of civil service, this will help develop a methodological basis for taking specific measures to improve the efficiency of the civil service reform.

Keywords: Russia; methodology; civil service; bureaucracy; administrative apparatus; socioeconomic development 


\section{REFERENCES}

Federal'nyi zakon ot 27 maia 2003 g. № 58-FZ «O sisteme gosudarstvennoi sluzhby Rossiiskoi Federatsii» [Federal Law No. 58-FZ "On the system of civil service in Russian Federation”, May 27, 2003] (2003). Sobranie zakonodatel' stva RF, June 2, no. 22, col. 2063 [online] Available at: http://www.szrf. $\mathrm{ru} /$ doc.phtml?nb=edition00\&issid=2004031000\&docid=41 (access date: 30.03 .2015 ). (In Russ.).

Ukaz Prezidenta RF ot 20 sentiabria 2010 g. № 1141 «O perechne dolzhnostei, periody sluzhby (raboty) v kotorykh vkliuchaiutsia v stazh gosudarstvennoi grazhdanskoi sluzhby dlia naznacheniia pensii za vyslugu let federal'nykh gosudarstvennykh grazhdanskikh sluzhashchikh» [President of Russian Federation. Decree No. 1141 "On the list of civil offices, holding which counts towards the record of state civil service for assigning pension for federal civil servants”, September 20, 2010] (2010). Sobranie zakonodatel'stva RF, September 27, no. 39, col. 4926 [online] Available at: http://www.szrf. $\mathrm{ru} /$ doc.phtml?nb=edition00\&issid=2010039000\&docid=57 (access date: 30.03 .2015$)$. (In Russ.).

«S gossluzhby ne ukhodiat» (2015) / Aleksandr L'vovich Safonov; besedovala Svetlana Sukhova ['One does not simply leave the civil service...': Svetlana Sukhova talks to Aleksandr L'vovich Safonov]. Ogonyok, no. 16, pp. 16-17. (In Russ.).

Voslensky, M. S. (1991) Nomenklatura. Gospodstvuiushchii klass Sovetskogo Soiuza [Nomenklatura: The Soviet Ruling Class]. Moscow, Sovetskaia Rossiia Publ. 624 p. (In Russ.).

Gimpel'son, V. E. (2002) Chislennost' $i$ sostav rossiiskoi biurokratii: Mezbdu sovetskoi nomenklaturoi $i$ gossluzbboi grazbdanskogo obshchestva [The number and composition of Russian bureaucracy: Between the Soviet-time nomenklatura and civil service of a civil society]. Moscow, GU VShE Publ. 40 p. (In Russ.).

Zaionchkovskii, P. A. (1978) Pravitel'stvennyi apparat samoderzbavnoi Rossii v XIX $v$. [State apparatus of autocratic Russia in the 19th century] Moscow, Mysl' Publ. 288 p. (In Russ.).

Kalabekov, I. G. (2010) Rossiiskie reformy $v$ tsifrakb i faktakb [Russian reforms in facts and figures]. $2^{\text {nd }}$ edition. Moscow, RUSAKI Publ. 270 p. (In Russ.).

Mel'nikov, V. P. and Nechiporenko, V. S. (2006) Gosudarstvennaia sluzbba v Rossii: otechestvennyi opyt organizatsii $i$ sovremennost' [Civil service in Russia: Organizational experience and contemporary situation] Moscow, RAGS Publ. 506 p. (In Russ.).

Obolonskii, A. V. (2015) Ocherk istorii rossiisko-sovetskoi biurokraticheskoi nomenklatury [A sketch of the history of Russian and Soviet bureaucratic nomenklatura]. Voprosy gosudarstvennogo i munitsipal' nogo upravleniia, no. 3, pp. 145-164. (In Russ.).

Rozenbaum, Iu. A. (1975) K poniatiiu upravlencheskikh kadrov [On the notion of cadres in public administration]. Pravovedenie, no. 6, pp. 20-25. (In Russ.). (In Russ.).

Sokolov, A. and Terent'ev, I. (2014) Issledovanie RBK: Skol'ko v Rossii chinovnikov i mnogo li oni zarabatyvaiut? [A study by RBK: How many civil servants Russia has and how much they earn]. $R B K$, October 15. [online] Available at: http://top.rbc.ru/economics/15/10/2014/543cfe56cbb20f8c $4 \mathrm{e} 0 \mathrm{~b}$ 98f2 (access date: 29.04.2015). (In Russ.).

Submission date: 20.10.2015.

Борщевский Георгий Александрович - кандидат исторических наук, доцент кафедры государственной службы и кадровой политики Института государственной службы и управления Российской академии народного хозяйства и государственной службы при Президенте РФ. Адрес: 119606, Россия, г. Москва, пр-т Вернадского, д. 84. Тел.: +7 (499) 956-01-26. Эл. адрес: ga.borshchevskiy@migsu.ranepa.ru

Borshchevskii Georgii Aleksandrovich, Candidate of History, Associate Professor, Department of Civil Service and Personnel Policy, Russian Presidential Academy of National Economy and Public Administration. Postal address: 84 Vernadsky Av., 119606 Moscow, Russian Federation. Tel.: +7 (499) 956-01-26. E-mail: ga.borshchevskiy@migsu.ranepa.ru 